\title{
Home ranges of East Pacific green turtles Chelonia mydas in a highly urbanized temperate foraging ground
}

\author{
Bradley D. MacDonald ${ }^{1,2, *}$, Rebecca L. Lewison ${ }^{1}$, Sheila V. Madrak ${ }^{1}$, \\ Jeffrey A. Seminoff ${ }^{2}$, Tomoharu Eguchi ${ }^{2}$ \\ ${ }^{1}$ Department of Biology, San Diego State University, 5500 Campanile Dr., San Diego, California 92182, USA \\ ${ }^{2}$ Protected Resources Division, Southwest Fisheries Science Center, National Marine Fisheries Service, \\ National Oceanic and Atmospheric Administration, 8901 La Jolla Shores Dr., La Jolla, California 92037, USA
}

\begin{abstract}
Green sea turtles Chelonia mydas use coastal areas as foraging grounds for the majority of their lives. Human development of coastlines is increasing, but the effects of urban development of foraging grounds on green turtles are poorly understood. We used acoustic telemetry to determine home ranges of green turtles during 2009 to 2011 in San Diego Bay, California, USA, which is a highly urbanized temperate foraging area. Adult and juvenile turtles $(\mathrm{n}=$ 25 , straight carapace length $=54.9$ to $102.5 \mathrm{~cm}$ ) were tracked for up to $370 \mathrm{~d}$. Based on the fixed kernel densities of 15 turtles, we found individual home range areas (95\% utilization distribution) were 2.09 to $8.70 \mathrm{~km}^{2}$ (mean $\pm \mathrm{SE}=5.51 \pm 0.57 \mathrm{~km}^{2}$ ), where each turtle used 1 or 2 core activity areas ( $50 \%$ utilization distribution). The home ranges of all turtles were exclusively in the southern portion of San Diego Bay, where eelgrass Zostera marina is abundant and where human activity is the lowest within the bay. Core activity areas coincided with eelgrass distribution or occurred adjacent to the warm water-effluent outfall of a power plant. Results from our study suggest that south San Diego Bay serves as important turtle habitat within the bay. Future monitoring is required to document the potential effects of changing environmental conditions, including closure of the power plant, on green turtles residing in San Diego Bay.
\end{abstract}

KEY WORDS: Sea turtle $\cdot$ Urbanized estuary $\cdot$ Power plant $\cdot$ Acoustic telemetry $\cdot$ Fixed kernel density estimator $\cdot$ Conservation

\section{INTRODUCTION}

Natural and anthropogenic factors change the amount of available habitat for a species through fragmentation, alteration, and loss (Harrison \& Bruna 1999, Fahrig 2003, Hobbs \& Yates 2003). A reduction of habitable space may directly influence an animal's habitat use and home range size. Home ranges are defined as the geographic area to which an animal normally restricts its activity and may vary with animal size, habitat, diet, sex, season, life stage, and other biotic and abiotic factors (Burt 1943, Bailey
1984, Kelt \& Van Vuren 1999). Human activities may further curtail home range extent, which is a particular problem for long-lived species that exhibit strong site fidelity, such as sea turtles (Ewers \& Didham 2006). Delineating home ranges and associated habitat use, particularly in human-dominated seascapes, is a critical step toward the design of effective conservation and management strategies for at-risk species (Kramer \& Chapman 1999, Lowe et al. 2003, Lindenmayer \& Fischer 2006).

Green sea turtles Chelonia mydas use coastal areas as foraging grounds for the majority of their lives 
(Musick \& Limpus 1997). Juveniles recruit to coastal foraging habitats at an approximate age of 2 to $7 \mathrm{yr}$ and maintain residency at one or several of these developmental habitats for 10 to 20 yr (Carr 1987, Pritchard 1997). Sexually mature individuals also occupy coastal foraging habitats between interannual reproductive migrations to nesting grounds, and often show fidelity to the same foraging grounds they used as juveniles (Musick \& Limpus 1997, Broderick et al. 2007). Once residency is established in a foraging ground, green turtles have been shown to display high site fidelity and occupy distinct home ranges (Limpus et al. 1994). Within foraging grounds, green turtles feed selectively on seagrasses, algae, and invertebrates (Bjorndal 1980, 1997, Seminoff et al. 2002b). Research has indicated that green turtle home ranges may largely be a function of food density and distribution: home ranges were small when food sources were dense (Mendonca 1983, Renaud et al. 1994) and were larger when food sources were scattered (Whiting \& Miller 1998, Seminoff et al. 2002a). Similarly, turtles may use one or more core areas within a more general home range in relation to foraging opportunities and resting habitat (Seminoff et al. 2002a, Makowski et al. 2006, Taquet et al. 2006). There is also some evidence that turtles respond to human-made structures. Renaud et al. (1994) found that juvenile green turtles were closely associated with jetty habitat in south Texas and were likely to forage along extensive algal mats that occur there. While the effects of human-mediated landscape alteration on turtle home ranges have not been directly studied, human activities strongly influence the coastal zone and anthropogenic impacts may affect the home ranges of green turtles in foraging grounds.

The presence of resident green turtles in San Diego Bay (SDB), a natural bay and port that lies adjacent to metropolitan San Diego, California, USA, has been documented since the 1800s and studied since the 1970s (Stinson 1984, McDonald et al. 1994). Green turtles in SDB belong to an endangered Mexico breeding population (National Resource Council 2010) that is considered to be part of the East Pacific stock that occupies Pacific coastal waters from South America to southern North America (Dutton et al. unpubl.). SDB serves as an important, year-round foraging site for approximately 60 green turtles, and new individuals continue to be recruited (Eguchi et al. 2010).

Turtles in SDB are known to aggregate near the South Bay Power Plant, a waterfront fossil-fuel power plant situated in south SDB that operated from 1960 to 2010 (Duke Energy South Bay LLC 2004, TurnerTomaszewicz \& Seminoff 2012; Fig. 1). During operation, the power plant used once-through cooling technology, drawing water from SDB to cool its 4 generators and emitting warm effluent water into an adjacent outfall channel. Green turtles habitually visited this effluent outfall channel during colder months concurrent with a drop in water temperatures in the more northern portions of SDB (Stinson 1984, McDonald et al. 1994). In addition to the power plant, SDB is also home to a high density of industrial, military, and recreational activities (US Department of the Navy 2010). The vast majority of military and industrial activities, as well as a high percentage of recreational boating, take place in the central and northern sections of the bay. These areas feature deep shipping channels and dock/marina access that is closer to the mouth of SDB (Fig. 1), while boat traffic in south SDB is primarily restricted to recreational boaters and fishers (US Department of the Navy 2010).

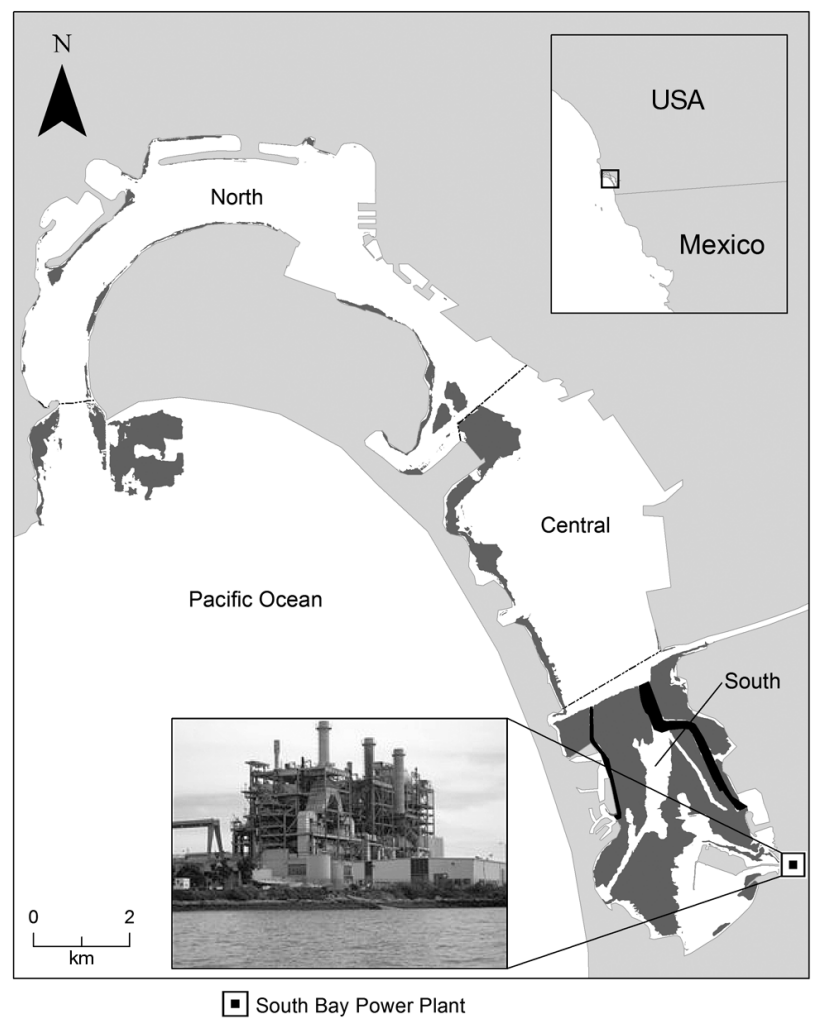

Fig. 1. Study area in San Diego Bay, California, USA. Dotted lines delineate the borders of north, central, and south San Diego Bay. Dark gray shading indicates eelgrass distribution, and black shading indicates boat channels on the eastern and western shores of south San Diego Bay. Eelgrass data provided by Merkel and Associates (2009) 
Our study explored the habitat use and movement patterns of 25 green turtles in SDB during 2009 to 2011 and tested the hypothesis that turtle habitat use is highly localized within SDB, co-occurring with the eelgrass habitat in south SDB and the warm effluent water of the South Bay Power Plant. We used acoustic telemetry to determine green turtle home ranges and to investigate the spatial and temporal overlap between human activities and resident East Pacific green turtles. The project provides necessary information on the habitat use of this long-lived species in the changing conditions of an urbanized environment.

\section{MATERIALS AND METHODS}

\section{Turtle capture}

Turtles were captured seasonally from November to April of 2009 to 2010 (Year 1, hereafter) and 2010 to 2011 (Year 2, hereafter), as part of a longterm study conducted by the National Oceanic and Atmospheric Administration (NOAA) National Marine Fisheries Service (NMFS) (see Eguchi et al. 2010). Weighted entanglement nets were deployed in waters adjacent to the South Bay Power Plant $\left(32^{\circ} 36^{\prime} \mathrm{N}, 117^{\circ} 06^{\prime} \mathrm{W}\right)$ from aboard a $15 \mathrm{ft}$ Boston Whaler and were checked at 30 min intervals. When a turtle was captured, it was immediately removed from the net and transferred to shore. Captured individuals were measured, weighed, sampled, and checked for external flipper tags and internal PIT tags. Inconel flipper tags (Style 681, National Band and Tag) were applied to the trailing edge of one front flipper and an internal PIT tag was injected into one of the front flippers of untagged individuals (Eguchi et al. 2010). A Sonotronics CT-Series acoustic transmitter was attached to the carapace of captured turtles using fiberglass cloth and resin laminate (Balazs et al. 1996). All turtles were released in the waters adjacent to the South Bay Power Plant.

\section{Acoustic telemetry}

Each transmitter emits a unique, cyclical pattern of pulses on a frequency between 35 and $40 \mathrm{kHz}$, which enables the identification of individual turtles. We tracked turtles with a Sonotronics TH-2 omnidirectional hydrophone, a Sonotronics DH-4 directional hydrophone, and a Sonotronics USR-08 ultrasonic receiver. Turtle presence was monitored from aboard a $17 \mathrm{ft}$ Boston Whaler with an $85 \mathrm{hp}$ outboard motor. We conducted weekly or biweekly surveys of SDB using a systematic spatial sampling grid, in which listening locations were spaced $500 \times 500 \mathrm{~m}$ (Fig. 2). The spacing of listening locations was determined by the detection limits of the hydrophone, ensuring that acoustic tags within a $500 \times 500 \mathrm{~m}$ area could be heard from at least one of the surrounding listening locations. At each listening location, the survey crew stopped the vessel and listened for turtle presence in the area using the omnidirectional hydrophone. When a tagged turtle could be detected on the omnidirectional hydrophone, a directional hydrophone was used to determine the approximate location (within $\sim 10$ to $20 \mathrm{~m}$ ) of the tagged turtle. The coordinates of this location were recorded using a handheld GPS once the turtle's transmitter could be heard loudly on the acoustic receiver's lowest gain setting or if the turtle was spotted visually. Once the turtle's location was recorded, the research vessel moved to the next listening location.

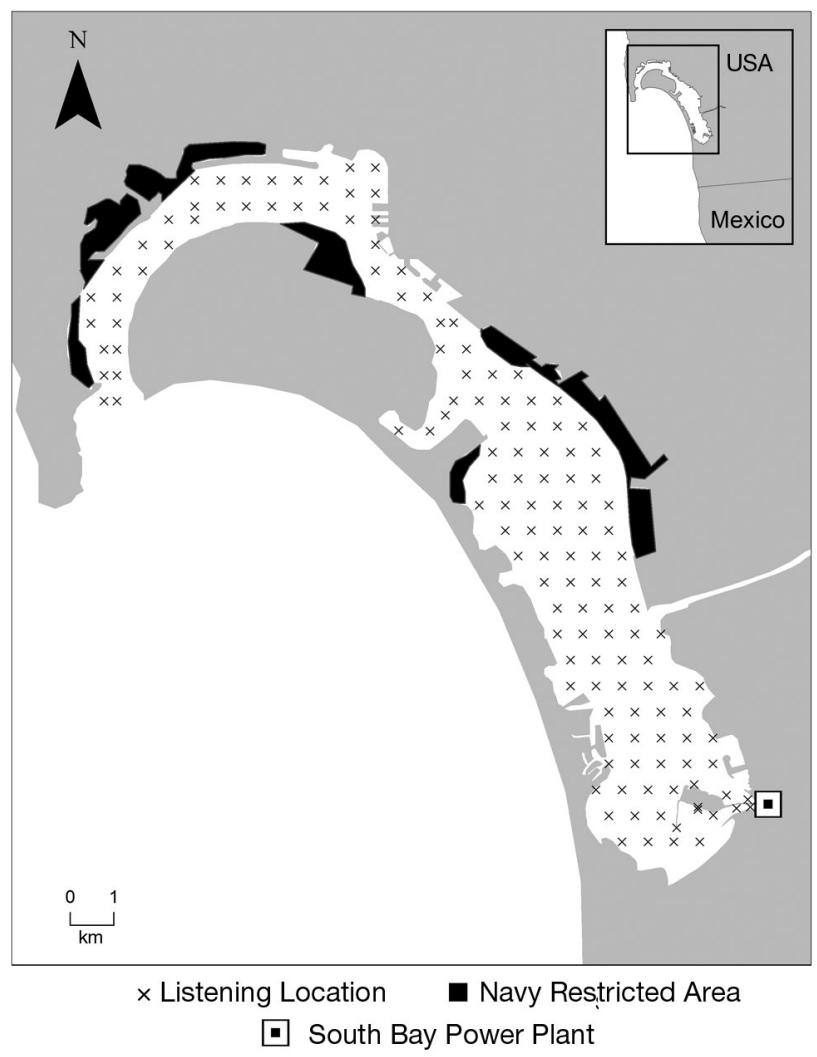

Fig. 2. San Diego Bay acoustic telemetry survey grid. Listening locations are indicated by ' $x$ '. Areas restricted to US Navy operations are shaded black 


\section{Home range estimation}

Home ranges were calculated using the fixed kernel density method (FKD) (Worton 1989). Kernel densities were summarized as $95 \%$ and $50 \%$ utilization distributions (UD), which are respectively denoted as home ranges and core activity areas within this study (Worton 1989). UDs for each turtle were constructed using GPS locations that were temporally separated by at least $4 \mathrm{~h}$ in order to reduce serial autocorrelation (Swihart \& Slade 1987, Hansteen et al. 1997, Schmid et al. 2003); the majority of turtle locations were separated by $>24 \mathrm{~h}$. All UDs were computed within ArcGIS 9.3 using the HRT Tools extension (http://flash.lakeheadu .ca/ arodgers/hre/) and HawthsTools extension (www.spatialecology.com) extensions.

The smoothing factor for each UD was determined using the reference bandwidth, calculated within HRT Tools. This value was subsequently used as a smoothing parameter in HawthsTools in order to generate UD polygons. Although using the reference bandwidth has been shown to over-smooth data, we opted to use this method because it is less sensitive to duplicate locations for an animal (Silverman 1986, Rodgers et al. 2007). When portions of a UD overlapped or extended onto land, land features were removed from the UD. The amount of overlap with the eastern and western boating channels of south SDB was calculated as a percentage of the overall home range and core area size.

We then generated incremental area plots to determine if a sufficient number of location points had been collected to yield a robust home range estimate for each turtle. Home range size was computed as a random sub-sample of locations $(>2)$ from each individual's total dataset. This process was then repeated, where the random sub-sample of locations was increased by one location with each subsequent iteration until partial-sample home ranges had been calculated for all samples sizes less than the individual's total number of locations. Partial-sample home ranges were then compared to the full-sample home range size of the individual to determine the average sample size at which home range size stabilized. Plots that become asymptotic or appear to be approaching an asymptote are considered to be robust home range estimates (Seminoff et al. 2002a).

To estimate a more general, population-level assessment of spatial habitat use, we also created a cumulative home range and core area estimate by pooling relocations from all tracked turtles. This method allowed us to consider the overall extent and 'hot spots' of turtle presence in SDB, and to include data from tracked turtles that did not have sufficient relocations for individual home ranges. Pooled data were also used to examine the seasonality of turtle movement in SDB. Home ranges and core areas were constructed from pooled turtle locations occurring between November and the end of March (hereafter termed winter) and April through October (hereafter termed non-winter). Our seasonal definitions were chosen based on water temperatures recorded at the intake of the South Bay Power Plant between January 2002 and December 2008 (T. Liebst pers. comm. $\left.{ }^{\underline{1}}\right)$. Mean temperatures were $16.8 \pm 0.2^{\circ} \mathrm{C}$ during winter months and $23.5 \pm 0.3^{\circ} \mathrm{C}$ during nonwinter months. To obtain a measure of uncertainty for pooled estimates, home ranges were recalculated with a systematic exclusion of 1 turtle from the data. This process was repeated until each turtle's data had been excluded from a home range calculation. Standard error was then calculated from the sample of home range estimations.

\section{Statistical analysis}

We compared the relationship between home range size and core area size using a simple linear correlation (Cohen \& Cohen 1983). A general linear model (GLM) was used to determine a relationship between home range size and potential predictors: year, number of locations, sex, and straight carapace length (SCL, cm) (Zar 1999). Mass was excluded from the model because it is correlated with SCL (Eguchi et al. 2012). Tracking duration was excluded because it is correlated with number of locations. A second GLM was used to test core area size as a dependent variable instead of home range size. Cumulative home range and core area estimates for winter and non-winter periods were compared using paired $t$ tests. All statistics were performed in SYSTAT 12 and evaluated at significance levels of alpha $=0.05$. Mean values and standard errors $( \pm \mathrm{SE})$ are reported.

\section{RESULTS}

\section{Acoustic telemetry}

In total, 25 turtles were captured: 8 adult males, 8 probable adult females, and 9 juvenile and/or subadult turtles of unknown sex (Table 1). The transmit-

\footnotetext{
1Tom Liebst, Dynergy South Bay LLC, 990 Bay Blvd., Chula Vista, California 91911, USA
} 
Table 1. Chelonia mydas. Morphometric and home range information for tracked turtles: year, denoted as '1' (2009 to 2010), '2' (2010 to 2011), or '1, 2' (tracked during both years); straight carapace length (SCL); mass; sex, classified as male $(\mathrm{M})$, probable female $(\mathrm{F})$, or unknown $(\mathrm{U})$; tracking duration, denoted as the number of days between an individual's first and last detection; number of relocations; and $95 \%$ and $50 \%$ utilization distributions (UDs), measured in $\mathrm{km}^{2}$. (-) no data

\begin{tabular}{|lccccccccc|}
\hline $\begin{array}{l}\text { Turtle } \\
\text { ID }\end{array}$ & Year & $\begin{array}{c}\text { SCL } \\
(\mathrm{cm})\end{array}$ & $\begin{array}{c}\text { Mass } \\
(\mathrm{kg})\end{array}$ & $\begin{array}{c}\text { Sex } \\
\text { duration }(\mathrm{d})\end{array}$ & $\begin{array}{c}\text { No. } \\
\text { relocations }\end{array}$ & $\begin{array}{c}95 \% \\
\text { UD }\end{array}$ & $\begin{array}{c}50 \% \\
\text { UD }\end{array}$ \\
\hline 1989 & 1 & 101.1 & 130 & $\mathrm{M}$ & 22 & 4 & - & - \\
1990 & 1,2 & 100.4 & 138 & $\mathrm{~F}$ & 310 & 30 & 7.03 & 1.227 \\
2116 & 2 & 102.0 & 136 & $\mathrm{M}$ & 127 & 20 & 8.4 & 0.727 \\
3004 & 1 & 101 & 153 & $\mathrm{~F}$ & 87 & 4 & - & - \\
3005 & 1,2 & 86.4 & 92 & $\mathrm{M}$ & 319 & 26 & 5.04 & 0.974 \\
4546 & 1 & 95.2 & 130 & $\mathrm{~F}$ & 160 & 12 & - & - \\
5806 & 2 & 95.5 & 138 & $\mathrm{M}$ & 166 & 18 & 3.13 & 0.872 \\
7218 & 2 & - & - & $\mathrm{U}$ & 65 & 6 & - & - \\
8356 & 1 & 97.2 & 130 & $\mathrm{M}$ & 0 & 0 & - & - \\
8370 & 1 & 101.8 & 132 & $\mathrm{~F}$ & 116 & 5 & - & - \\
11761 & 1 & 100.8 & 133 & $\mathrm{~F}$ & 133 & 17 & 4.04 & 0.88 \\
13585 & 1 & 102.5 & 147 & $\mathrm{~F}$ & 180 & 24 & 4.6 & 1.206 \\
13690 & 1,2 & 80.9 & 62 & $\mathrm{U}$ & 370 & 53 & 4.89 & 1.01 \\
13962 & 2 & 88.3 & 96 & $\mathrm{M}$ & 47 & 6 & - & - \\
23647 & 2 & 103.1 & 140 & $\mathrm{~F}$ & 67 & 3 & - & - \\
23648 & 1 & 81.4 & - & $\mathrm{U}$ & 10 & 4 & - & - \\
33145 & 1,2 & 74.5 & 58 & $\mathrm{U}$ & 247 & 40 & 2.799 & 0.472 \\
33149 & 1 & 71.1 & 48 & $\mathrm{U}$ & 160 & 14 & 7.63 & 2.027 \\
88129 & 1,2 & 97.7 & 115 & $\mathrm{M}$ & 87 & 15 & 2.09 & 0.49 \\
88329 & 1 & 65.3 & 35 & $\mathrm{U}$ & 163 & 19 & 6.11 & 1.21 \\
88416 & 1 & 87 & 81 & $\mathrm{~F}$ & 198 & 24 & 6.27 & 2.13 \\
88466 & 1 & 54.9 & 18 & $\mathrm{U}$ & 148 & 18 & 8.62 & 4.04 \\
97376 & 1 & 69.4 & 43 & $\mathrm{U}$ & 0 & 0 & - & - \\
98157 & 2 & 59.6 & 27 & $\mathrm{U}$ & 175 & 16 & 8.7 & 2.36 \\
98310 & 2 & 98.5 & 138 & $\mathrm{M}$ & 140 & 20 & 3.34 & 0.903 \\
& & & & & & & & \\
\hline
\end{tabular}

dinates (>5 consecutive times) without visual confirmation of the turtle and without any observed movement away from the GPS location over an extended monitoring period $(>4 \mathrm{~h})$. If we ceased to regularly detect a transmitter during acoustic surveys of

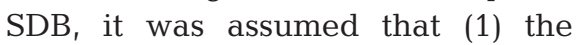
transmitter battery had expired, (2) the transmitter was otherwise damaged or dislodged from the turtle, or (3) the turtle had departed from SDB.

\section{Home range estimation}

Based on incremental area plots, we estimated that home range size stabilized at a sample size of 14 relocations (Fig. 3). Because this number of relocations yielded robust home range estimates (e.g. $\geq 80 \%$ of the home range size with all available relocations), we used it as a threshold and were able to calculate home ranges for 15 out of 23 individuals. Of these 15 turtles, 6 were from Year 1, 4 were from Year 2, and 5 were tracked in both years (Table 1). The average $( \pm \mathrm{SE})$ overall home range estimate was $5.51 \pm 0.57 \mathrm{~km}^{2}$ and the average core area was $1.37 \pm 0.24 \mathrm{~km}^{2}$ (Table 1, Fig. 4). Core area was positers of 2 individuals were dislodged near a submerged barge before any tracking could take place. These turtles were excluded from all subsequent analyses. The average $( \pm \mathrm{SE})$ number of relocations was $11.15 \pm 2.43$ for turtles tracked in Year 1, $12.71 \pm$ 2.80 for turtles in Year 2, and $32.80 \pm 6.45$ for those that were tracked during both years. Tag retention determined the tracking duration and the final number of relocations for each turtle, as transmitters are frequently dislodged or damaged when turtles scrape their carapaces on hard surfaces, a type of 'shell cleaning' behavior exhibited by this species (Heithaus et al. 2002). A tag was presumed to be dislodged if it was repeatedly found at the same coor-

Fig. 3. Chelonia mydas. Incremental area plot for 15 green turtles tracked in San Diego. The upper and lower limits of each solid line are based on the interquartile range. Circles indicate the mean. Dotted lines indicate $\mathrm{n}=14$ locations on the abscissa and $80 \%$ of final home range size on the ordinate tively correlated with home range size $(\mathrm{R}=0.70$; $\mathrm{p}=$ 0.003). We found that SCL was negatively related to core area size $(F=8.29, \mathrm{p}=0.02)$, suggesting that larger turtles occupied smaller core areas. None of the

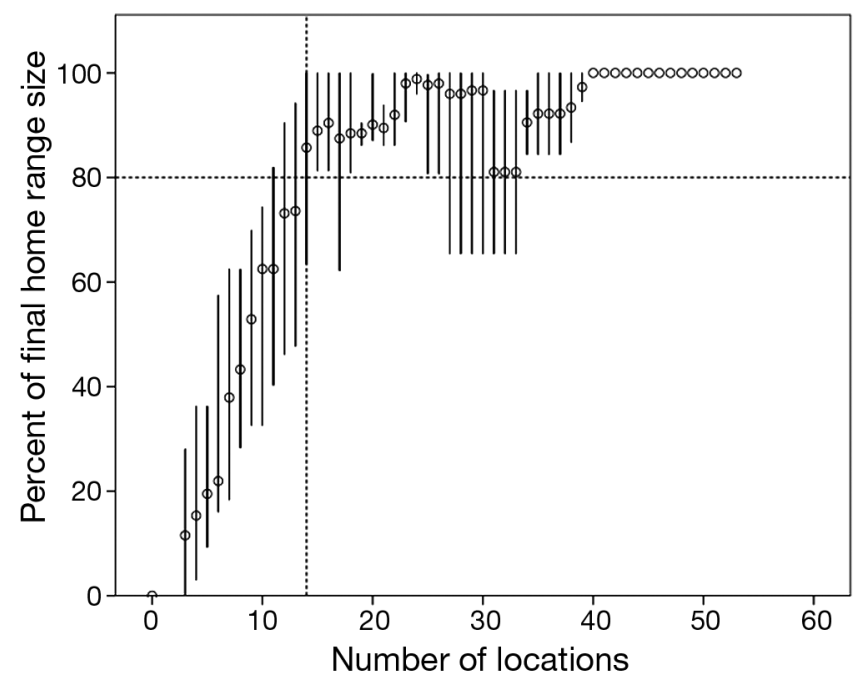


Table 2. Chelonia mydas. Summary of general linear model parameter estimates based on green turtle $95 \%$ and $50 \%$ utilization distributions (UDs). Years included were 2009 to 2010, 2010 to 2011, or both years; No. locations refers to the number of independent locations of individual turtles from manual tracking efforts; sex was classified as male, female, or unknown; and straight carapace length (SCL) was measured in $\mathrm{cm}^{*}{ }^{*}$ : statistical significance; $(-)$ not applicable

\begin{tabular}{|lcccc|}
\hline Parameter & SS & MS & F-ratio & $\mathrm{p}$ \\
\hline $\mathbf{9 5} \%$ UD & & & & \\
Year & 6.01 & 3.00 & 0.61 & 0.57 \\
No. locations & 0.24 & 0.24 & 0.05 & 0.83 \\
Sex & 6.33 & 3.16 & 0.64 & 0.55 \\
SCL & 5.31 & 5.31 & 1.08 & 0.33 \\
Error & 39.32 & 4.91 & - & - \\
$\mathbf{5 0 \%}$ UD & & & & \\
Year & 0.40 & 0.20 & 0.50 & 0.63 \\
No. locations & 0.02 & 0.02 & 0.05 & 0.82 \\
Sex & 1.52 & 0.76 & 1.89 & 0.21 \\
SCL & 3.34 & 3.34 & 8.29 & $0.02{ }^{*}$ \\
Error & 3.23 & 0.40 & - & - \\
& & & & \\
\hline
\end{tabular}

other predictor variables (year, number of relocations, sex) had a statistically significant effect on core area size (Table 2). There was no statistically significant relationship between home range size (95\% UD) and any predictor variables (Table 2 ).

In the case of individuals whose $50 \%$ UD was split across 2 areas $(n=9)$, one of these core areas always occurred along the effluent outfall channel of South Bay Power Plant. Frequently, the second core area overlapped with documented eelgrass Zostera marina distribution in south SDB (Figs. 1 \& 4). South Bay Power Plant core areas were smaller than the eelgrass core areas $\left(0.42 \pm 0.09\right.$ vs. $\left.0.68 \pm 0.19 \mathrm{~km}^{2}\right)$, but these differences were not statistically significant $(t=1.00 ; \mathrm{p}=0.33)$. Overall core area size was $1.67 \pm$ $0.54 \mathrm{~km}^{2}$ for turtles that used 1 core area and $1.19 \pm$ $0.17 \mathrm{~km}^{2}$ for turtles that used 2 core areas; differences were not statistically significant $(t=1.01 ; \mathrm{p}=$ 0.32 ). The eastern and western boating channels of south SDB constituted an average of $4.5 \pm 1.1 \%$ of home range areas and $3.6 \pm 1.6 \%$ of core areas.

Using data for all turtles, the cumulative home range size was $6.53 \pm 0.05 \mathrm{~km}^{2}$ and contained 2 core areas: (1) along the effluent outfall channel and jetty habitat of South Bay Power Plant $\left(0.66 \mathrm{~km}^{2}\right)$ and (2) co-occurring amidst the south SDB eelgrass pastures $\left(0.85 \mathrm{~km}^{2}\right.$, Fig. 5$)$. Taken together, the total core area size was $1.51 \pm 0.02 \mathrm{~km}^{2}$. Winter and non-winter $95 \%$ UDs (or home ranges) were similarly shaped and extended westwards from South Bay Power Plant and northwards into south SDB (Fig. 5). The non-winter home range $\left(7.28 \pm 0.07 \mathrm{~km}^{2}\right)$ was significantly larger than the winter home range $\left(5.59 \pm 0.09 \mathrm{~km}^{2}\right)(t=14.7$; $\mathrm{p}<0.001)$. The non-winter core area $\left(1.83 \pm 0.03 \mathrm{~km}^{2}\right)$ was located in the middle of south SDB and overlapped with eelgrass distributions in the area. In contrast, the winter core area $\left(0.81 \pm 0.04 \mathrm{~km}^{2}\right)$ was associated with the South Bay Power Plant outfall channel and jetty habitat and was significantly smaller than the non-winter core area $(t=12.3 ; \mathrm{p}<0.001)$.

\section{DISCUSSION}

Coastal inlets and estuaries serve as foraging grounds for green turtles in many regions, and are often modified and degraded by human activities. The present study represents one of the first comprehensive assessments of spatial ecology for green turtles in an urbanized foraging ground. We used a robust monitoring protocol to regularly survey the entirety of SDB and found that all turtle home ranges were found exclusively in south SDB.

Turtle presence near the South Bay Power Plant appears to be strongly linked to the area's thermal profile and benthic habitat that is not typical of the rest of the bay (low traffic, soft sediment channels). Marine animals have been reported to use power plant effluent channels previously, including West Indian manatees in Florida (Laist \& Reynolds 2005a,b), green turtles in Chile (Donoso \& Dutton 2000), and green turtles in Long Beach, California (an area north of $\mathrm{SDB}_{\text {; }} \mathrm{D}$. Lawson pers. comm.). As a thermally responsive species, green turtles may exploit power plant effluents as thermal refuges, particularly during colder periods, which may accommodate energetics and growth rates. For example, green turtles in SDB have been demonstrated to exhibit growth rates comparable to green turtles in the Caribbean (Dutton \& Dutton 1999, Eguchi et al. 2012). In our study, the cumulative core area (50\% UD) was associated with the South Bay Power Plant's warm water effluent outfall channel during winter months (Fig. 5). A similar pattern of seasonal, localized habitat selection has been reported in loggerhead sea turtles by Schofield et al. (2009), in which females showed affinity towards transient patches of warm water during colder months but did not exhibit any selection during warmer months. Indeed, the seasonal usage of warmwater effluent by green turtles in our study is supported by historical capture rates at the power plant, which are higher in the winter and lower in spring months (Eguchi et al. 2010). In non-winter months, the cumulative core area was found to overlap with 

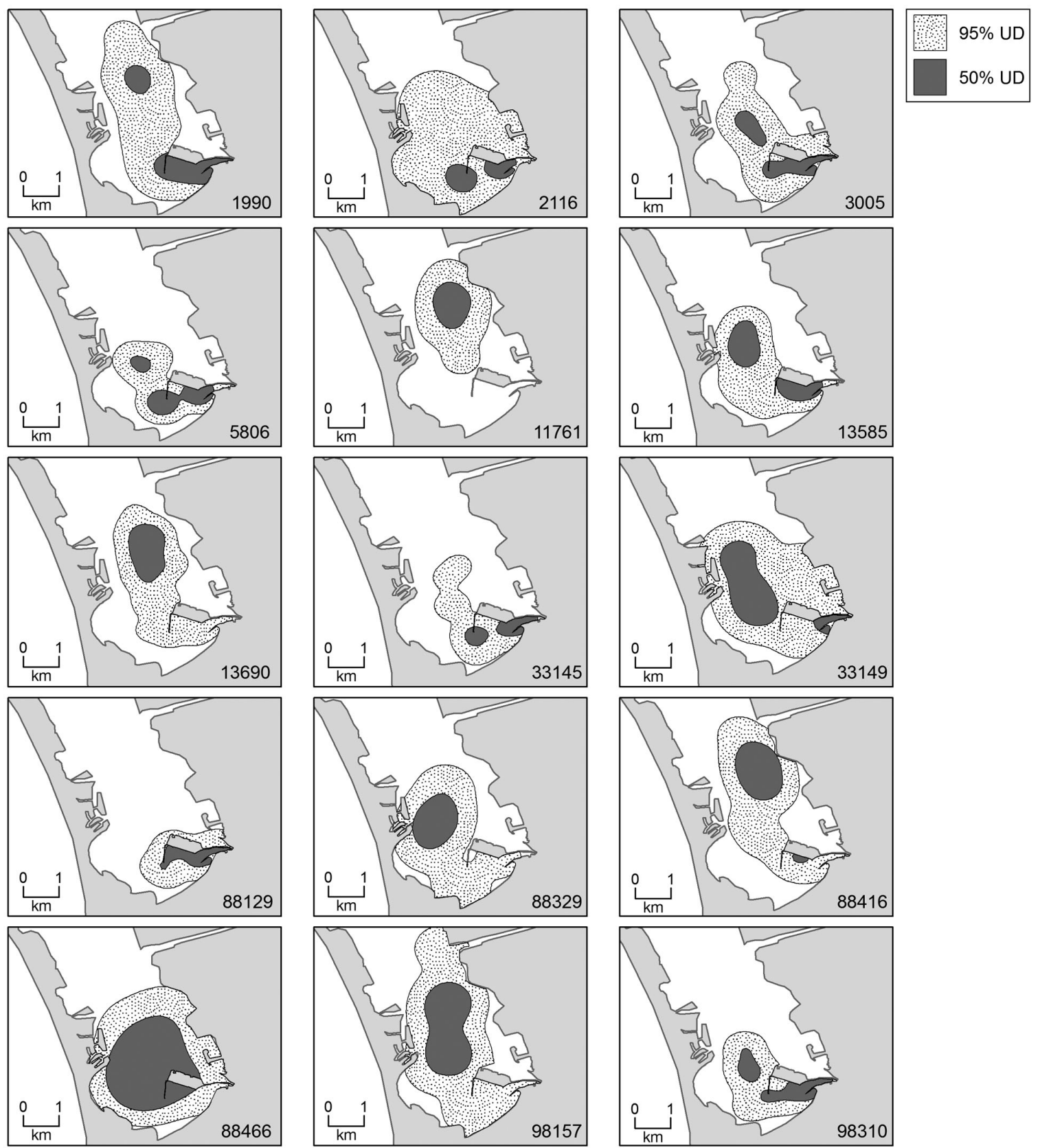

Fig. 4. Chelonia mydas. Home range maps of green turtles tracked in San Diego Bay. Turtle IDs are listed in the lower right corner of each panel. UD: utilization distribution

the known distribution of eelgrass pastures in south SDB (Fig. 5). Diet composition analysis of green turtles in SDB has found that these individuals consume invertebrates and eelgrass (Lemons et al. 2011), suggesting that the observed overlap may be driven by foraging behaviors.

The average home range of resident turtles in our study $\left(5.51 \pm 0.57 \mathrm{~km}^{2}\right)$ was comparable to other green turtle home ranges (Whiting \& Miller 1998, Makowski et al. 2006, Senko et al. 2010) but was smaller than re- ported home ranges of East Pacific green turtles in the Gulf of California $\left(15.37 \pm 2.80 \mathrm{~km}^{2}\right.$; Seminoff et al. 2002a). In SDB, all turtles used either 1 or 2 core areas, which was also consistent with green turtles at other sites (e.g. Seminoff et al. 2002a, Makowski et al. 2006, Senko et al. 2010). It is common for turtles to show fidelity to multiple locations within a foraging ground, moving between nighttime resting areas to preferred foraging habitat in the day (Brill et al. 1995, Makowski et al. 2006, Taquet et al. 2006), a topic that merits fur- 


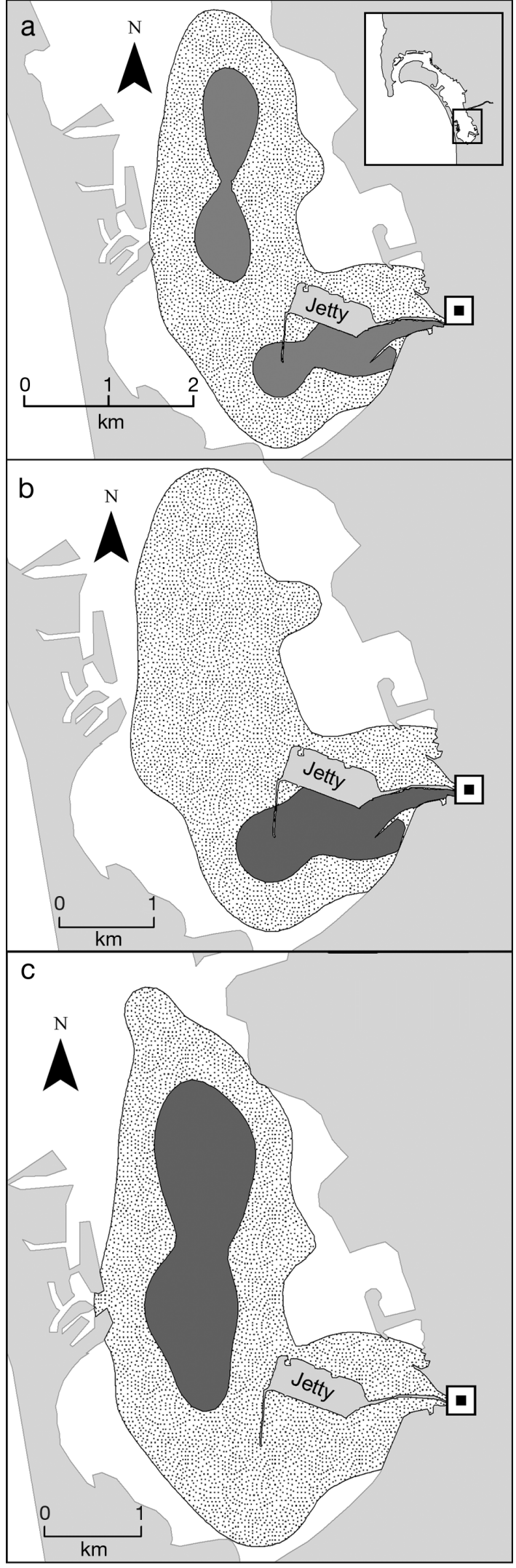

95\% UD $\square$ 50\% UD $\square$ South Bay Power Plant ther research in SDB. We found a significant negative relationship between SCL and core area size and a similar qualitative relationship between SCL and home range size, suggesting that larger, adult turtles utilized smaller activity areas. Some studies have found no statistically significant relationships between green turtle size and use areas (Seminoff et al. 2002a, Makowski et al. 2006, Senko et al. 2010), whereas Mendonca (1983) found a positive relationship between body size and home range size. However, Mendonca (1983) studied juveniles, while our study population included both adults and juveniles. It is unclear what is driving the relationship between turtle size and the size of use areas, although we propose 3 potential explanations: (1) turtles are using different food sources at different size classes and consequently have activity areas dependent upon the spatial distribution of their diets; (2) larger turtles outcompete smaller turtles for access to better quality habitat and, with high quality habitat, large turtles require a smaller home range; or (3) larger, presumably older turtles are more familiar with the local distribution of resources and are able to forage more efficiently as a result. Data suggest that turtles are not foraging on different food sources at different sizes; Lemons et al. (2011) found no relationship between size and the mean proportion densities of putative prey items of green turtles in SDB. The substantial overlap of home ranges and core areas among turtles tracked in the present study also suggests that larger turtles are not outcompeting or otherwise excluding smaller turtles from accessing use areas. Thus, the most likely explanation is that larger turtles use smaller core areas as a result of increased familiarity and foraging efficiency within the foraging ground. Fidelity to a foraging ground over time is well documented in green turtles (Musick \& Limpus 1997, Broderick et al. 2007), and multiple recaptures of individuals from 1990 to 2011 (Eguchi et al. 2010) confirm the site fidelity of turtles foraging in SDB. In the absence of direct data to support the hypothesis that larger turtles are more familiar with local resource distribution, however, we urge cautious interpretation of the observed relationship between body size and use area until further data are available.

The present study indicates that habitat use in urbanized foraging areas may be dichotomous, with

Fig. 5. Chelonia mydas. (a) Cumulative $(\mathrm{n}=404)$, (b) winter (between November and the end of March; $\mathrm{n}=240$ ), and (c) non-winter (April through October; $\mathrm{n}=164$ ) home range maps constructed using all green turtle locations. UD: utilization distribution 
turtles using both highly modified habitat, e.g. the South Bay Power Plant's man-made effluent channel and jetty habitat, but also relying heavily on areas that are less impacted (i.e. eelgrass pastures). Turtles in SDB showed little to no overlap with the boating channels adjacent to eelgrass areas, though this may be because turtles did not have to traverse boat channels to access other use areas. This is not the first time sea turtles have been reported using heavily modified areas to forage; Kemmerer et al. (1983) reported acoustic detections of loggerhead sea turtles in and around Canaveral Channel in Florida, and Renaud et al. (1994) found that juvenile green turtles in a Texas harbor were frequently found foraging along a man-made jetty that abutted a heavily trafficked boating channel. The potential for diverse patterns of habitat use among populations of turtles in different urbanized areas likely depends on the types of human activities in the particular area as well as how turtles use the area, such as for foraging or resting. The relative abundance of eelgrass habitat and the warm-water effluent of the power plant in southern SDB appear to have resulted in green turtles localizing their activities to a very specific portion of SDB, whereas turtle habitat in other urban foraging areas may not necessarily be connected or densely grouped. Future studies of other urbanized foraging areas will be necessary to elucidate the differences in turtle behavior and movement when resources are highly localized vs. scattered and when human activities and impacts are diverse.

With the decommissioning of the South Bay Power Plant in December 2010, human use of south SDB may change as the waterfront area is developed for other purposes. In the years preceding the power plant's shut down, turtle capture rates were lower when temperatures in the effluent area were similar to temperatures in the rest of the bay (TurnerTomaszewicz \& Seminoff 2012). Though tracked turtles continued to visit the effluent area throughout the winter and spring of 2011, insufficient data exist to predict the long-term responses of turtles to the lack of warm effluent water. The presence of green turtles in SDB pre-dates the operation of the South Bay Power Plant and south SDB provides habitat that has been used as a natural foraging area for this species for centuries (Stinson 1984). This suggests that, although green turtles show affinity for warm water habitat (Spotila et al. 1997), such as the artificial microclimate created by the South Bay Power Plant effluent, it is not necessarily essential to their survival within SDB. With new juveniles continuing to recruit to SDB (Eguchi et al. 2010), continued study of how turtles respond to the dynamic changes taking place in an already impacted ecosystem is needed.

Effective management of green turtles in SDB, given its intense utilization by industrial, military, and recreational entities, is contingent upon knowing where and when turtle activities overlap with human activities. The results of the present study suggest that resident turtles likely do not spend much, if any, time foraging in central or north SDB, where human activities are greatest. Though we acknowledge that all of the turtles in the present study were captured next to the South Bay Power Plant, capture has been attempted in other areas of the bay without success across the 20+ yr of monitoring in SDB. Further, in our bay-wide surveys for tagged turtles, we never acoustically detected nor visually spotted any turtles in north SDB and only twice detected turtles in central SDB. Similarly, spotting surveys conducted via kayak throughout SDB have almost exclusively located turtles in south SDB (P. Dutton pers. comm.). Turtle sightings are occasionally reported in central and north SDB, but we expect these are likely transient turtles that enter the bay during warmer months. During the winter, water temperatures in central and north SDB are lower ( $\sim 10$ to $14^{\circ} \mathrm{C}$; S. Madrak unpubl. data) than the suggested lower thermal limit of approximately $15^{\circ} \mathrm{C}$ for green sea turtles (Read et al. 1996, Moon et al. 1997, Spotila et al. 1997), essentially creating a thermal barrier against movement into those portions of SDB for year-round residents (Eguchi et al. 2010). These thermal constraints, in conjunction with historical data and the fact that the majority of capture events took place during winter months, suggest that turtles captured during this study are a representative sample of the majority of turtles foraging in SDB.

Our data highlight the critical importance of habitat in south SDB for resident green turtles, particularly because eelgrass is abundant there and is only sparsely scattered in other areas of the bay. South SDB is a unit of the SDB National Wildlife Refuge, a status that offers protection to green turtles as well as numerous species of seabirds, shorebirds, and estuarine habitat in the southern end of the bay. Signs posted throughout south SDB limit boaters outside of channels to $8 \mathrm{~km} \mathrm{~h}^{-1}$ in order to prevent incidental turtle strikes, a known source of turtle mortality in SDB (NMFS \& USFWS 1998), but compliance may be limited (M. Bishop pers. comm.). Though quantitative data are not available, recreational boat traffic in South SDB peaks during summer months (Carson et al. 2002, US Department of the Navy 2010). Turtles increased their use of eelgrass habitat in south SDB dur- 
ing the spring and summer (Fig. 5), coinciding with increased recreational boat traffic in the same area. Thus, turtles may be at greater risk of boat strikes during summer months. Further research is needed to assess how turtle response to boat presence in shallow areas may influence the likelihood of boat strikes (Hazel et al. 2007). Improved enforcement of existing protective measures, such as the $8 \mathrm{~km} \mathrm{~h}^{-1}$ speed limit for boats operating in south SDB, would reduce potential interactions between boaters and turtles.

As development intensifies along coastlines worldwide, understanding how green turtles use urbanized foraging areas will lead to more robust management strategies for this species of conservation concern. Patterns of site fidelity and detailed knowledge of animal movements within an area serve as a powerful framework within which to evaluate conservation strategies (Kramer \& Chapman 1999, Seminoff et al. 2002a, Burgman et al. 2005). Effective turtle management and protection in coastal areas will rely on strategies specifically tailored to protect natural communities and system dynamics within urbanized habitats.

Acknowledgements. Financial and logistical support was generously provided by the Unified Port of San Diego, the NOAA Southwest Fisheries Science Center, COAST, Sonotronics Inc., South Bay Power Plant LLC, and the San Diego State University Department of Biology. We thank the following individuals for their tremendous support in the field: S. Coates, A. Gaos, T. Grimes, D. Ho, C. Jackson, G. Lemons, N. Magana, D. Mahoney, R. Moens, D. Prosperi, C. Turner, and the entire NOAA-NMFS team that assisted with turtle capture. We particularly thank K. Stewart and R. LeRoux for valuable comments on this manuscript, and further thank R. LeRoux for invaluable assistance in sonic transmitter attachment and coordination of turtle capture. All research and animal handling was carried out under National Marine Fisheries Service Permit \#1591 and was in compliance with IACUC protocol at San Diego State University. This is contribution no. 22 of the Coastal and Marine Institute Laboratory, San Diego State University.

\section{LITERATURE CITED}

Bailey JA (1984) Principles of wildlife management. WileyLiss, New York, NY

Balazs GH, Russel KM, Beaver SC (1996) Procedures to attach a satellite transmitter to the carapace of an adult green turtle (Chelonia mydas). In: Keinath JA, Barnard DE, Musick JA, Bell BA (eds) Proc 15th Annu Symp Sea Turtle Biol Conserv. NOAA Tech Memo, NMFS-SEFSC487. US Department of Commerce, p 21-26

Bjorndal KA (1980) Nutrition and grazing behavior of the green turtle Chelonia mydas. Mar Biol 56:147-154

Bjorndal KA (1997) Foraging ecology and nutrition of sea turtles. In: Lutz PL, Musick JA (eds) The biology of sea turtles. CRC Press, Boca Raton, FL, p 199-231
Brill RW, Balazs GH, Holland KN, Chang RKC, Sullivan S, George JC (1995) Daily movements, habitat use, and submergence intervals of normal and tumor-bearing juvenile green turtles (Chelonia mydas L.) within a foraging area in the Hawaiian Islands. J Exp Mar Biol Ecol 185:203-218

Broderick AC, Coyne MS, Fuller WJ, Glen F, Godley BJ (2007) Fidelity and over-wintering of sea turtles. Proc Biol Sci 274:1533-1538

Burgman MA, Lindenmayer DB, Elith J (2005) Managing landscapes for conservation under uncertainty. Ecology 86:2007-2017

$>$ Burt WH (1943) Territoriality and home range concepts as applied to mammals. J Mammal 24:346-352

Carr A (1987) New perspectives on the pelagic stage of sea turtle development. Conserv Biol 1:103-121

Carson R, Damon M, Johnson L, Miller J (2002) Transitioning to non-metal antifouling paints on marine recreational boats in San Diego Bay. California Department of Boating and Waterways, Sacramento, CA

Cohen J, Cohen P (1983) Applied multiple regression/correlation analysis in the behavioral sciences, 2nd edn. Lawrence Erlbaum, New York, NY

Donoso M, Dutton PH (2000) Forage area identified for green turtles in northern Chile. In: Mosier A, Foley A, Brost B (eds) Proc 20th Annu Symp Sea Turtle Biol Conserv. NOAA Tech Memo, NMFS-SEFSC-477. US Department of Commerce, p 274

Duke Energy South Bay LLC (2004) South Bay Power Plant cooling water system effects on San Diego Bay, Vol 1: Compliance with Section 316(1) of the Clean Water Act for the South Bay Power Plant. San Diego Regional Water Quality Control Board, San Diego, CA

Dutton DL, Dutton PH (1999) Accelerated growth in San Diego Bay green turtles? In: Proc 17th Annu Symp Sea Turtle Biol Conserv. NOAA Tech Memo, NMFS-SEFSC415. US Department of Commerce, p 164-165

Eguchi T, Seminoff JA, LeRoux R, Dutton PH, Dutton DM (2010) Abundance and survival rates of green turtles in an urban environment: coexistence of humans and an endangered species. Mar Biol 157:1869-1877

Eguchi T, Seminoff JA, LeRoux R, Prosperi D, Dutton DL, Dutton PH (2012) Morphology and growth rates of the green turtle (Chelonia mydas) in a northern-most temperate foraging ground. Herpetologica 68:76-87

> Ewers RM, Didham RK (2006) Confounding factors in the detection of species responses to habitat fragmentation. Biol Rev Camb Philos Soc 81:117-142

> Fahrig L (2003) Effects of habitat fragmentation on biodiversity. Annu Rev Ecol Syst 34:487-515

> Hansteen TL, Andreassen HP, Ims RA (1997) Effects of spatio-temporal scale on autocorrelation and home range estimators. J Wildl Manag 61:280-290

> Harrison S, Bruna E (1999) Habitat fragmentation and largescale biodiversity: what do we know for sure? Ecography 22:225-232

> Hazel J, Lawler IR, Marsh H, Robson S (2007) Vessel speed increases collision risk for the green turtle Chelonia mydas. Endang Species Res 3:105-113

> Heithaus MR, McLash JJ, Frid A, Dill LM, Marshall GJ (2002) Novel insights into green sea turtle behavior using animal-borne video cameras. J Mar Biol Assoc 82: 1049-1050

> Hobbs RJ, Yates CJ (2003) Impacts of ecosystem fragmentation on plant populations: generalizing the idiosyncratic. Aust J Bot 51:471-488 
Kelt DA, Van Vuren D (1999) Energetic constraints and the relationship between body size and home range in mammals. Ecology 80:337-340

Kemmerer A, Timko R, Burkett S (1983) Movement and surfacing behavior patterns of loggerhead sea turtles in and near Canaveral Channel, Florida (September and October 1981). NOAA Tech Memo, NMFS-SEFC-112. US Department of Commerce

Kramer DL, Chapman MR (1999) Implications of fish home range size and relocation for marine reserve function. Environ Biol Fishes 55:65-79

Laist DW, Reynolds JE (2005a) Influence of power plants and other warm-water refuges on Florida manatees. Mar Mamm Sci 21:739-764

Laist DW, Reynolds JE (2005b) Florida manatees, warmwater refuges, and an uncertain future. Coast Manag 33: 279-295

Lemons G, Lewison R, Komoroske L, Gaos A and others (2011) Trophic ecology of green sea turtles in a highly urbanized bay: insights from stable isotopes and mixing models. J Exp Mar Biol Ecol 405:25-32

Limpus CJ, Couper PJ, Read MA (1994) The green turtle Chelonia mydas in Queensland: population structure in a warm temperate feeding area. Mem Queensl Mus 35: 139-154

Lindenmayer DB, Fischer J (2006) Habitat fragmentation and landscape change: an ecological and conservation synthesis. Island Press, Washington, DC

Lowe CG, Topping DT, Cartamil DP, Papastamatiou YP (2003) Movement patterns, home range, and habitat utilization of adult kelp bass Paralabrax clathratus in a temperate no-take marine reserve. Mar Ecol Prog Ser 256:205-216

Makowski C, Seminoff JA, Salmon M (2006) Home range and habitat use of juvenile Atlantic green turtles (Chelonia mydas L.) on shallow reef habitats in Palm Beach, Florida, USA. Mar Biol 148:1167-1179

McDonald D, Dutton P, Mayer D, Merkel K (1994) Review of the green turtles of south San Diego Bay in relation to the operations of the SDG\&E South Bay Power Plant. San Diego Gas \& Electric Co, San Diego, CA

Mendonca MT (1983) Movements and feeding ecology of immature green turtles (Chelonia mydas) in a Florida lagoon. Copeia 1983:1013-1023

Merkel and Associates (2009) 2008 San Diego Bay eelgrass inventory and bathymetry update. US Navy Region Southwest Naval Facilities Engineering Command and San Diego Unified Port District, San Diego, CA

Moon DY, MacKenzie DS, Owens DW (1997) Simulated hibernation of sea turtles in the laboratory: feeding, breathing frequency, blood $\mathrm{pH}$, and blood gases. J Exp Zool 278:372-380

Musick JA, Limpus CJ (1997) Habitat utilization and migration in juvenile sea turtles. In: Lutz PL, Musick JA (eds) The biology of sea turtles. CRC Press, Boca Raton, FL, p $137-155$

National Resource Council (2010) Assessment of sea-turtle status and trends: integrating demography and abundance. The National Academies Press, Washington, DC

NMFS \& USFWS (National Marine Fisheries Service \& US Fish and Wildlife Service) (1998) Recovery plan for US Pacific populations of the East Pacific green turtle (Chelonia mydas). National Marine Fisheries Service, Silver Spring, MD
Pritchard PCH (1997) Evolution, phylogeny, and current status. In: Lutz PL, Musick JA (eds) The biology of sea turtles. CRC Press, Boca Raton, FL, p 2-24

Read MA, Grigg GC, Limpus CJ (1996) Body temperatures and winter feeding in immature green turtles, Chelonia mydas, in Moreton Bay, Southeastern Queensland. J Herpetol 30:262-265

Renaud ML, Carpenter JA, Williams JA (1994) Activities of juvenile green turtles, Chelonia mydas, at a jettied pass in South Texas. Fish Bull 93:586-593

Rodgers AR, Carr AP, Beyer HP, Smith L, Kie JG (2007) HRT: home range tools for ArcGIS, Version 1.1. Ontario Ministry of Natural Resources, Peterborough

Schmid JR, Bolten AB, Bjorndal KA, Lindberg WJ, Percival HF, Zwick PD (2003) Home range and habitat use by Kemp's Ridley turtles in west-central Florida. J Wildl Manag 67:196-206

Schofield G, Bishop CM, Katselidis KA, Dimopoulos P, Pantis JD, Hays GC (2009) Microhabitat selection by sea turtles in a dynamic thermal marine environment. J Anim Ecol 78:14-21

Seminoff JA, Resendiz A, Nichols WJ (2002a) Home range of green turtles Chelonia mydas at a coastal foraging area in the Gulf of California, Mexico. Mar Ecol Prog Ser 242: 253-265

Seminoff JA, Resendiz A, Nichols WJ (2002b) Diet of East Pacific green turtles (Chelonia mydas) in the Central Gulf of California, Mexico. J Herpetol 36:447-453

Senko J, Koch V, Megill WM, Carthy RR, Templeton RP, Nichols WJ (2010) Fine scale daily movements and habitat use of East Pacific green turtles at a shallow coastal lagoon in Baja California Sur, Mexico. J Exp Mar Biol Ecol 391:92-100

Silverman BW (1986) Density estimation for statistics and data analysis. Chapman \& Hall, London

Spotila JR, O'Connor MP, Paladino FV (1997) Thermal biology. In: Lutz PL, Musick JA (eds) The biology of sea turtles. CRC Press, Boca Raton, FL, p 297-314

Stinson ML (1984) Biology of sea turtles in San Diego Bay, California, and in the northeastern Pacific Ocean. MS thesis, San Diego State University, CA

Swihart RK, Slade NA (1987) Influence of sampling interval on estimates of home-range size. J Wildl Manag 49: 1019-1025

Taquet C, Taquet M, Dempster T, Soria M, Ciccione S, Roos D, Dagorn L (2006) Foraging of the green sea turtle Chelonia mydas on seagrass beds at Mayotte Island (Indian Ocean), determined by acoustic transmitters. Mar Ecol Prog Ser 306:295-302

Turner-Tomaszewicz C, Seminoff JA (2012) Turning off the heat: impacts of power plant decommissioning on green turtle research in San Diego Bay. Coast Manag 40:73-87

US Department of the Navy (2010) San Diego Bay integrated natural resources management plan, draft September 2010. Naval Facilities Engineering Command Southwest, Port of San Diego, Tierra Data Inc, Escondido, CA

Whiting SD, Miller JD (1998) Short term foraging ranges of adult green turtles (Chelonia mydas). J Herpetol 32: 330-337

> Worton BJ (1989) Kernel methods for estimating the utilization distribution in home-range studies. Ecology 70 : 164-168

Zar JH (1999) Biostatistical analysis, 4th edn. Prentice Hall, Englewood Cliffs, NJ

Submitted: November 23, 2011; Accepted: May 14, 2012

Proofs received from author(s): July 30, 2012 